\title{
INFLUÊNCIA SOCIAL, MINORIAS ATIVAS E DESENVOLVIMENTO MORAL: ENSAIO TEÓRICO SOBRE A REPRESENTATIVIDADE POLÍTICA BRASILEIRA
}

\author{
INFLUENCIA SOCIAL, MINORÍAS ACTIVAS Y DESARROLLO MORAL: \\ ENSAYO TEÓRICO SOBRE LA REPRESENTATIVIDAD POLÍTICA BRASILEÑA \\ SOCIAL INFLUENCE, ACTIVE MINORITIES AND MORAL DEVELOPMENT: \\ THEORETICAL ESSAY ON BRAZILIAN POLITICAL REPRESENTATIVENESS
}

http://dx.doi.org/10.1590/1807-0310/2018v30173402

Paulo Roberto Grangeiro Rodrigues

Universidade de Taubaté, São Paulo/SP, Brasil

\begin{abstract}
RESUMO
Apresentamos um ensaio teórico sobre a associação entre as formas de influência social: obediência, identificação e internalização, e o desenvolvimento moral desde a criança até o adulto, passando pelos níveis: Pré-convencional, Convencional e Pós-Convencional - consecutivos em função do desenvolvimento do pensamento, postulando a existência do Pensamento de Grupo (groupthink) entre o pensamento egocêntrico próprio do nível Pré-Convencional da infância e o sociocêntrico próprio do nível Pós-Convencional, possível para o adulto. O groupthink se estabelece no nível Convencional e se perpetua no adulto devido aos processos de dominação, não só no âmbito organizacional, mas também em todos os grupos sociais, a começar pela família. $\mathrm{O}$ objetivo foi analisar as consequências de tal predomínio na representatividade política nacional, por meio da análise das "Bancadas" da Câmara dos Deputados, e as possibilidades de sua superação por meio da ação de minorias ativas no Congresso Nacional.
\end{abstract}

Palavras-chave: desenvolvimento moral; desenvolvimento cognitivo; influência social; minorias ativas; pensamento de grupo.

\section{RESUMEN}

Se presenta un ensayo teórico sobre la asociación entre las formas de influencia social: el cumplimiento, la identificación y la internalización y el desarrollo moral de niño a adulto, a través de los niveles: Pre-convencional, Convencional y Post-convencional - consecutivos con el desarrollo del pensamiento, postulando la existencia del pensamiento de tipo pensamiento de grupo (groupthink) entre el pensamiento egocéntrico proprio del nivel Pre-convencional de la infancia y el pensamiento sociocéntrico propio de lo nivel Post-convencional, posible al adulto. El groupthink se establece en el nivel convencional y se perpetúa en adultos debido a los procesos de dominación, no sólo a nivel de organizaciones, sino también en todos los grupos sociales, empezando por la familia. El objetivo fue analizar las consecuencias de tal predominio en la representatividad política nacional, por medio del análisis de las "Bancadas" de la Cámara de Diputados, y las posibilidades de superarlo a través de la acción de las minorías activas no Congreso Nacional.

Palabras clave: desarrollo moral; desarrollo cognitivo; influencia social; minorías activas; pensamiento de grupo.

\begin{abstract}
We present a theoretical essay on the association between the forms of social influence: compliance, identification and internalization - and moral development from child to adult, through the levels: Pre-conventional, Conventional and Postconventional - consecutive with the development of thought, postulating the existence of Groupthink between the egocentric thinking - proper of the Pre-conventional level in the infancy, and sociocentric thinking, proper of the Postconventional level, possible to the adult. The Groupthink is established in the Conventional level and is perpetuated in the adults due to processes of domination, not only into the organizations but also in all social groups, beginning within the family. The objective was to analyze the consequences of this predominance in the national political representativeness, through the analysis of the "Bancadas" of the Chamber of Deputies, and the possibilities of overcoming them through the action of active minorities in Congress.
\end{abstract}

Keywords: moral development; cognitive development; social influence; active minorities; groupthink. 


\section{Introdução}

Este ensaio visa à compreensão, sob um foco psicossocial, de um fato aparentemente estranho da democracia brasileira: como a composição do poder legislativo está tão distante da composição da população brasileira, sob qualquer critério, e como os eleitores acabam elegendo como maioria quem não os representa diretamente, e sim representantes de grupos econômicos e/ou familiares que estarão ali defendendo apenas os próprios interesses. Trata-se de tentar entender a qualidade da democracia brasileira em termos da sua representatividade realizada pelo voto direto. Para isso recorremos a uma base teórica de psicologia social que relaciona os processos de influência social com os de desenvolvimento moral, e permite compreender como as relações de dominação - com base no poder econômico-político - podem levar as pessoas dominadas a permanecerem em um estado de "menoridade" psíquica, e como isso se reflete nas escolhas políticas que se expressam nas eleições diretas. Focalizamos então os resultados das quatro últimas eleições para Presidente e da última para a Câmara Federal, com dados da Justiça Eleitoral e de organizações de análise do Congresso Nacional, visando a avaliar se as eleições refletem processos de influência social que funcionam de modo a permitir essa baixa representatividade popular na política brasileira, comprometendo negativamente nossa democracia. Analisamos a representatividade por meio das adesões dos deputados federais às "bancadas" de que participam. Há, entre as bancadas, minorias, e dentre elas a dos Direitos Humanos, a que mais pode se aproximar dos interesses populares. Então partimos para a busca de uma forma de se usar a influência social de minorias ativas para se conquistar mais poder e espaço político para a população brasileira, por meio de seus representantes (de seus anseios por justiça social), eleitos, ainda que seja uma minoria quantitativa. Será possível que essa minoria, agindo em conjunto e obtendo adesões, conquiste crescentemente poder para defender e aprovar as agendas democráticas, como a concretização do usufruto universal dos Direitos Humanos?

\section{Os processos de influência social}

As ciências sociais, incluindo a Psicologia Social, têm demonstrado que somos uma espécie que parte de uma situação inicial de vida de extrema dependência não para a completa independência, porém para a interdependência entre adultos. Podemos dizer que nenhuma criança se torna humana a não ser entre humanos, e ninguém se tornará adulto capaz de agir conforme a interdependência saudável para todos - a não ser sob a influência de adultos que promovam esta igualdade. Com isso, torna-se fundamental estudar os processos de influência social a que nós estamos sujeitos, visando a compreender as condições psicossociais para o bem-estar subjetivo. Para isso, adotamos primeiramente, neste ensaio, o referencial teórico de um autor que devota toda sua vida acadêmica ao estudo e aplicação dos processos de influência social.

A teoria da influência social de Herbert Kelman (1958) assume que há três processos de influência que uma pessoa $(\mathrm{P})$ pode sofrer de outra $(\mathrm{O})$ : obediência ou submissão (compliance), identificação (identification) e internalização (internalization), que descrevemos: obediência ocorre quando $\mathrm{P}$ aceita a influência de $\mathrm{O}$ ou de um grupo de modo a obter uma reação favorável - seja ganhar uma recompensa específica ou evitar uma punição específica, ou ganhar aprovação ou evitar desaprovação. Identificação ocorre quando $\mathrm{P}$ aceita a influência de $\mathrm{O}$ ou de um grupo de modo a estabelecer ou manter uma relação autodefinidora satisfatória. A relação pode ser baseada em reciprocidade - em que a pessoa procura cumprir as expectativas do outro, ou pode ser baseada em modelação - em que a pessoa procura assumir o papel do outro, ou parte dele. Internalização ocorre quando $\mathrm{P}$ aceita a influência de $\mathrm{O}$ ou de um grupo de modo a manter a congruência de ações e crenças com seu próprio sistema de valores. Congruência com os valores pode assumir a forma de consistência cognitiva - em que o comportamento induzido é percebido como conducente à maximização dos valores, ou a forma de adequação afetiva - em que o comportamento induzido é percebido como em continuidade com o autoconceito da pessoa (Kelman, 2006)

As motivações subjacentes a cada processo são subdivididas entre aquelas reguladas por interesses instrumentais (assegurar obter recompensas e evitar punições, viver de acordo com as expectativas do próprio papel, maximizar os valores) e aquelas reguladas por interesses de automanutenção (gerenciar a imagem pública, viver os papéis de acordo com os próprios modelos, confirmar o autoconceito) (Kelman, 2006). Kelman distingue esses processos em termos de antecedentes e consequentes, resumindo-os conforme a Tabela 1.

Kelman também postula que os três processos podem acontecer simultaneamente em algum nível em todos os indivíduos, "dependendo da situação em que estes se encontram, da relação particular que é posta em jogo, e das circunstâncias do momento" (Kelman, 
Tabela1. Resumo das distinções entre os três processos de influência social

\begin{tabular}{|c|c|c|c|}
\hline $\begin{array}{c}\text { INFLUÊNCIA } \\
\text { ANTECEDENTES }\end{array}$ & $\begin{array}{l}\text { OBEDIÊNCIA } \\
\text { (SUBMISSÃO) }\end{array}$ & IDENTIFICAÇÃO & INTERNALIZAÇÃO \\
\hline $\begin{array}{l}\text { 1. BASE PARA A IMPORTÂNCIA } \\
\text { DA INDUÇÃO: }\end{array}$ & $\begin{array}{l}\text { Preocupação com o efeito } \\
\text { social do comportamento }\end{array}$ & $\begin{array}{l}\text { Preocupação com o } \\
\text { apoio social do compor- } \\
\text { tamento }\end{array}$ & $\begin{array}{l}\text { Preocupação com o } \\
\text { valor de congruência } \\
\text { comportamental }\end{array}$ \\
\hline $\begin{array}{l}\text { 2. FONTE DE PODER DO AGENTE } \\
\text { INDUTOR: }\end{array}$ & $\begin{array}{l}\text { Meios de controle } \\
\text { (Contingência) }\end{array}$ & Atratividade & Credibilidade \\
\hline $\begin{array}{l}\text { 3. MANEIRA DE ATINGIR } \\
\text { DOMIINIO DA CONDUTA } \\
\text { INDUZIDA: }\end{array}$ & $\begin{array}{l}\text { Limitação da escolha de } \\
\text { comportamento }\end{array}$ & $\begin{array}{l}\text { Delimitação das exigên- } \\
\text { cias do papel }\end{array}$ & $\begin{array}{l}\text { Reorganização da } \\
\text { relação entre meios } \\
\text { e fins }\end{array}$ \\
\hline \multicolumn{4}{|l|}{ CONSEQUENTES } \\
\hline $\begin{array}{l}\text { 1. CONDIÇÕES DE EXECUÇÃO } \\
\text { DA CONDUTA INDUZIDA: }\end{array}$ & $\begin{array}{l}\text { Fiscalização pelo agente } \\
\text { influenciador }\end{array}$ & $\begin{array}{l}\text { Relevância da relação } \\
\text { para com o agente }\end{array}$ & $\begin{array}{l}\text { Relevância dos } \\
\text { valores para com o } \\
\text { tema específico }\end{array}$ \\
\hline $\begin{array}{l}\text { 2. CONDIÇÕES DE MUDANÇA } \\
\text { E EXTINÇÃO DA CONDUTA } \\
\text { INDUZIDA: }\end{array}$ & $\begin{array}{l}\text { Percepção modificada das } \\
\text { condições para recompensa } \\
\text { social }\end{array}$ & $\begin{array}{l}\text { Percepção modifi- } \\
\text { cada das condições para } \\
\text { relações satisfatórias de } \\
\quad \text { autodefinição }\end{array}$ & $\begin{array}{c}\text { Percepção modifi- } \\
\text { cada das condições } \\
\text { para maximização de } \\
\text { valor }\end{array}$ \\
\hline
\end{tabular}

\section{TIPO DE SISTEMA COMPORTA- MENTAL NO QUAL A CONDUTA INDUZIDA ESTÁ IMERSA:}

Exigências externas de um ambiente específico
Expectativas definidoras de um papel específico
Sistema de valores da pessoa

Baseado em (Kelman, 2006, p. 5). . Tradução livre.

2006, p. 15). Isso pode ser facilmente exemplificado nas relações de trabalho, em que há simultaneamente a preocupação com o salário e benefícios (processo de obediência), com a afiliação com o grupo de trabalhadores (processo de identificação) e com a congruência entre valores pessoais e organizacionais no trabalho (processo de internalização) (O’Reilly III, Chatman, 1986, citados por Medeiros, Albuquerque, Siqueira, \& Marques, 2003). No entanto, a teoria de Kelman também permite a inferência de que esses processos ocorram pela primeira vez em sequência, no decorrer do desenvolvimento psicológico da pessoa, começando com a obediência, na infância. Isso porque no texto de Kelman sobre orientação política (2006) o autor estabelece explicitamente uma relação entre os três processos e os três consecutivos níveis do raciocínio moral descritos por Kohlberg, que serão descritos em seguida: Nível Pré-Convencional, Nível Convencional e Nível Pós-Convencional (2006, p. 16).

\section{Os estágios do desenvolvimento moral}

Kohlberg, em sua abordagem cognitiva do desenvolvimento moral (Kohlberg \& Hersh, 1977), propõe que esse, acompanhando o desenvolvimento do indivíduo, tem os níveis assim definidos: PréConvencional, Convencional e Pós-Convencional. Esses três níveis se estabelecem em dependência destes fatores: “(a) o nível de desenvolvimento cognitivo; (b) o ambiente; (c) as interações sociais e (d) as oportunidades de desempenho do papel" (Fini, 1991, p. 69).

Os três níveis se subdividem em dois estágios cada. A teoria de Kohlberg também postula que:

Estágios implicam uma sequência invariável, em ordem constante. Isto não quer dizer que todo indivíduo alcança determinado estágio com a mesma idade. A ordem não implica cronologia constante ou 
que todos alcancem cada estágio na mesma idade, mas que não ocorrem saltos. $\mathrm{O}$ indivíduo não chega ao estágio 3 sem passar pelo estágio 2. (Fini, 1991, p. 67).

Diante dessa associação entre o desenvolvimento moral e a influência social, podemos partir para uma formulação dinâmica com foco na suscetibilidade do indivíduo em desenvolvimento para os três processos de influência, relacionando com o desenvolvimento moral e as formas de pensamento possíveis e dominantes em cada etapa desse desenvolvimento, com base nos estágios do desenvolvimento cognitivo definidos por Piaget que deram base às formulações de Kohlberg. Para isso, vamos agora descrever os níveis e estágios desse desenvolvimento moral. Apresentamos na Tabela 2 um resumo: mútua" (Fini, 1991, p. 63), estando a consciência orientada por uma "ética universal" (Rique, Camino, Moreira, \& Abreu, 2013, p. 245) no estágio 6, mesmo que isso possa implicar questionar ou não cumprir as leis vigentes em uma dada sociedade.

A coincidência das descrições das formas de comportamento típicas de cada estágio pelos dois teóricos nos esclarece que há um desenvolvimento moral possível com base na maturação cognitiva, os indivíduos nunca pulam estágios e o movimento é sempre para o próximo estágio (pode haver voltas em comportamentos típicos de níveis anteriores, apenas por "trauma extremo" (Kohlberg \& Hersh, 1977, p. 54). Porém argumentamos neste ensaio teórico, com base na afirmação de Kohlberg e Hersh de que alguns indivíduos alcançam o estágio

Tabela 2. Níveis e estágios do desenvolvimento moral segundo Kohlberg

\begin{tabular}{llll}
\hline $\begin{array}{l}\text { NÍVEIS DO DESEN- } \\
\text { VOLVIMENTO MORAL }\end{array}$ & NÍVEL I & NíVEL II & NíVEL III \\
& Pré-Convencional & $\begin{array}{l}\text { Pós-convencional, autônomo } \\
\text { ou nível de princípios }\end{array}$ \\
\hline ESTÁGIOS: & $\begin{array}{l}\text { Estágio 1 - orientação para a } \\
\text { obediência e castigo }\end{array}$ & $\begin{array}{l}\text { Estágio 3 - orientação } \\
\text { do bom menino e boa } \\
\text { menina }\end{array}$ & $\begin{array}{l}\text { Estágio } 5 \text { - orientação con- } \\
\text { tratual legalista }\end{array}$ \\
\cline { 2 - 4 } & $\begin{array}{l}\text { Estágio 2 - orientação inge- } \\
\text { nuamente egoísta }\end{array}$ & $\begin{array}{l}\text { Estágio 4 - orientação } \\
\text { de manutenção da au- } \\
\text { toridade e ordem social }\end{array}$ & $\begin{array}{l}\text { Estágio 6 - orientação de } \\
\text { consciência ou princípios }\end{array}$ \\
\hline
\end{tabular}

Ao realçarmos que Kelman define também os três processos de influência social como baseados em orientações dominantes em $\mathrm{P}$, fica mais nítida a associação:

Na obediência, há a orientação para a regra ("rule"), própria da moralidade pré-convencional, em que há "deferência egocêntrica, sem questionamento, para o poder ou prestígio superior ou tendência para evitar aborrecimentos" no estágio 1, e "igualitarismo ingênuo e orientação para troca e reciprocidade" no estágio 2 (Fini, 1991, p. 63).

Na identificação, há a orientação para o papel ("role"), própria da moralidade convencional, em que há "conformidade com imagens estereotipadas ou papéis naturais..." no estágio 3, e "consideração pelas expectativas merecidas dos outros" no estágio 4 (Fini, 1991, p. 63).

$\mathrm{Na}$ internalização, há orientação para valor ("value"), própria da moralidade pós-convencional, em que há dever "de evitar, de forma geral, a violação dos direitos dos outros e da vontade e bem-estar da maioria" no estágio 5, e "orientação para consciência, como agente dirigente, e segundo respeito e confiança de princípios enquanto outros não (1977), que pode haver estagnação em função dos processos de influência social, continuamente sofridos por P. Nosso foco aqui será agora principalmente estas possíveis "estagnações" no desenvolvimento moral, como resultado da influência social sofrida, e as formas típicas de pensamento de que $\mathrm{P}$ predominantemente se utiliza em cada estágio em função da passagem do egocentrismo da infância para o possível "sociocentrismo" da vida adulta. Para isto precisamos argumentar sobre o desenvolvimento do pensamento, que também passa por essas três etapas, conforme Kohlberg as definiu com base em Piaget (Kohlberg \& Hersh, 1977).

Nas palavras de Fini (1991, p. 67): “estágios constituem estruturas de conjunto ou sistemas organizados de respostas que implicam diferenças qualitativas nos modos de pensamento". Também Rique et al. explicam:

Quanto ao desenvolvimento cognitivo, o período intuitivo pré-operacional é necessário para atingir o Nível I - Pré-convencional. Em seguida, é necessário ter consolidado as operações concretas para uma pessoa atingir o Nível II - Moral Convencional. Da mesma forma, é preciso que as operações formais 
tenham sido desenvolvidas completamente para que essa pessoa possa atingir o Nível III - Moral Pósconvencional. (Rique et al., 2013, p. 246)

Então necessariamente assumiremos que no desenvolvimento - da criança ao jovem adulto antes vem a obediência relacionada ao nível PréConvencional, depois a identificação relacionada ao nível Convencional e finalmente a internalização relacionada ao nível Pós-Convencional.

\section{Os modos do pensamento em cada estágio do desenvolvimento moral}

Sabemos que no nível Pré-Convencional há apenas o pensamento egocêntrico, o que explica a capacidade limitada de raciocínio moral das crianças (em geral, e de alguns adultos delinquentes, ou com retardo mental severo). Esse é um tipo de pensamento autocentrado e concreto, preso ao presente. Sabemos também que no nível Pós-Convencional há o pensamento sociocêntrico (Paín, 1992), no qual o jovem (e concretamente uma minoria de adultos) pode raciocinar incluindo "o ponto de vista das relações que regulam os sistemas sociais" (Rique et al., 2013, p. 246), com base em ideias abstratas como Justiça, equidade, humanidade. Isso é baseado no fato de que "o adolescente supõe que o que é real não esgota o possível, mas que haverá uma prioridade do possível sobre o real, como instância de sistemas mais amplos" (Paín, 1992, p. 40).

E qual seria a forma de pensamento própria do nível Convencional, onde está a maior parte dos adolescentes e também dos adultos? Já sabemos que não há "operações formais" no nível Convencional, ainda que já tenha sido superado o egocentrismo infantil. Trata-se de uma forma de pensamento em transição, já operacional, porém ainda concreto. Sabemos também, pela associação postulada por Kelman (2006), que é o período da influência por identificação. Kohlberg confirma essa ideia ao afirmar que no nível Convencional há muita conformidade ao que é visto de maneira estereotipada como comportamento "natural" ou da maioria (Kohlberg \& Hersh, 1977). Buscando na literatura a descrição de alguma forma de pensamento na transição entre o pensamento egocêntrico e o pensamento sociocêntrico, encontramos a teoria do pensamento grupal ou Pensamento de Grupo (Groupthink) (Janis, 1971). O Pensamento de Grupo foi definido inicialmente no âmbito da psicologia organizacional como uma situação de grupo "em que as pressões por conformidade impedem que o grupo avalie as alternativas de ação de maneira racional e crítica"1. "A eficiência mental do indivíduo, seu senso de realidade e o seu julgamento moral sofrem como resultado da pressão do grupo" (Robbins, Judge, \& Sobral, 2010, p. 282).

Podemos argumentar que pessoas que já tenham alcançado o nível Pós-Convencional possam chegar a ceder à pressão do grupo pela conformidade, ficando inibidas em expressar seu pensamento crítico e se eximindo em questões morais em que uma maioria julga com parâmetros do nível Convencional em situações claramente injustas se julgadas segundo princípios universais. Porém é mais esperado que pessoas no nível Convencional sejam muito mais suscetíveis ao Pensamento de Grupo, em função de sua busca por cumprir expectativas, e tendência à manutenção da "ordem social". Especialmente se há uma "liderança" autoritária no grupo, ou seja, aquela que não escuta as discordâncias e que não age de forma imparcial, dado que há em P uma orientação para "manutenção da autoridade". Também temos que lembrar que a maioria das pessoas adultas poderia estar no nível Pós-Convencional, mas estas estão ainda no nível Convencional (Edwards, 1980, Fini, 1991), podendo quase sempre exercer pressão psicológica para a conformidade de julgamento e decisões em qualquer grupo, simplesmente por estarem em maioria, mesmo quando defendem decisões com base em percepções obviamente erradas, conforme demonstrado no experimento clássico de Asch (1977).

Podemos argumentar que o Pensamento de Grupo também ocorra em diversas configurações sociais e não só nos grupos de trabalho, a começar nas famílias, indo até as comunidades e instituições. Kelman afirmou a generalização dos processos de influência social: "O quadro deve ser igualmente aplicável a qualquer outra unidade social - sociedade, comunidade, organização, instituição - ou qualquer outro grupo de identidade ou coletividade..." (Kelman, 2006, p. 17). Trata-se de um fenômeno psicossocial a ser superado, pois o que ocorre de fato é a imposição do pensamento de um só sobre os outros nos grupos, refletindo relações de dominação e a manutenção de pessoas em estado de "subdesenvolvimento" psicológico.

Já em 1785 o filósofo Kant (citado por Crochík, 2006) propunha a ideia do "imperativo categórico"2 como indicador do mais alto nível de moralidade e consequentemente descrevia a "menoridade", isto é, a permanência em um estado psicológico infanto-juvenil, da maioria das pessoas adultas: "Os preconceitos, segundo Kant - e ele utilizava esse termo - são incutidos nos homens, que são impedidos e se impedem de pensar por si próprios" (Crochík, 2006, p. 44). Esse não é um estado psicológico insuperável, dado que, como reitera Crochík, "a libertação do poder sempre foi possível, e se 
ainda não ocorreu é porque os homens, até hoje, foram mantidos em um estado de menoridade, como enfatizou Kant” (2006, p. 116). Estão lançadas as condições para o predomínio do Pensamento de Grupo, em que um declara o que pensa e os outros concordam, o que mais se mantém quanto mais autoritárias as relações e as personalidades decorrentes.

E não se trata apenas de nível de escolarização para garantir um nível moral imaginado como correspondente. Poderíamos pensar que os estudantes universitários, enquanto futuros ocupantes de cargos superiores nas organizações, em papéis de liderança, pudessem exercer os papéis de disseminadores e defensores do pensamento moral Pós-Convencional por meio da Identificação provocada naqueles seus liderados. Porém, pesquisas feitas desde 1983 avaliando empiricamente o nível de julgamento moral - conforme a teoria de Kohlberg - em amostras de universitários brasileiros por meio do Moral Judgment Interview-MJ (Colby \& Kohlberg, 2010, citado por Rique et al., 2013) mostram algo diferente. A pesquisa de Biaggio (citada por Rique et al., 2013) em 1983 com 29 universitários mostrou que estavam nos Estágios 3 e 4 - ambos no nível Convencional -, assim como a pesquisa de Koller em 1990 (citada por Rique et al., 2013) com 180 universitários entre 18 e 25 anos. Mais recentemente, uma pesquisa de 2011 com 97 universitários brasileiros com média de idade de 19 anos demonstrou que 62 deles estavam no Estágio 4, e apenas 18 no Estágio 5 - já PósConvencional, com apenas 1 no Estágio 6, da orientação pela ética universal (Rique et al., 2013). Talvez tenha havido algum avanço, mas ainda incipiente. Não há razões para pensar que a atual população universitária brasileira em geral divirja significativamente dessa amostra de 2011.

\section{Do comportamento político dos cidadãos em uma sociedade autoritária}

Evidentemente Kelman também explorou em teoria as consequências políticas para o fato de as pessoas serem diferentemente suscetíveis aos processos de influência social. Estudando o envolvimento dos indivíduos no sistema político nacional, afirmou que "Indivíduos operando no nível da identificação são suscetíveis de estar em conformidade com exigências autoritárias sob menos vigilância do que aqueles no nível da obediência e com menos questionamento do que aqueles no nível da internalização" (Kelman \& Hamilton, 1989, citado por Kelman, 2006, p. 13).

Com esse referencial teórico, podemos analisar como se dão as influências sociais na escolha dos membros do governo federal no processo eleitoral, e os impactos dos estágios do raciocínio moral e do tipo de pensamento associado da maioria da população votante, na qualidade da democracia da nossa nação.

Dado que a maioria da população está no nível Convencional de pensamento moral, essa maioria exerce uma forte pressão psicológica para a conformidade nesse nível de julgamento moral, agindo pela conservação da sociedade como ela está e em defesa da autoridade vigente. Mas ocorrem situações em que conservar a sociedade é perpetuar injustiças, e defender a autoridade formal vigente pode ser um apoio a uma ditadura, ou a um totalitarismo. É necessária sempre a defesa dos valores universais fundamentais para a Justiça, aplicando o princípio da equidade. É preciso haver lideranças políticas com pensamento moral Pós-Convencional, para lutar pela criação de novas leis e novas práticas do poder, em que não haja nem injustiça nem dominação do ser humano pelo ser humano. No entanto, essa minoria tem que saber como se organizar e agir para enfrentar a legitimação do pensamento de uma maioria, por unanimidade, que revela o Pensamento de Grupo, em que um "líder" diz e todos concordam e fazem o que esse determina, o que é um processo comum na democracia "representativa".

Seja no Executivo, seja no Legislativo, há representantes eleitos pelos votantes, com ideias apoiadas por esses eleitores. Ocorre que o programa em comum da maioria pode não ser o mais avançado ou mais bem pensado em termos da defesa e prática política de valores universais; lembremo-nos das pesquisas que afirmam que por volta da metade dos brasileiros (Datafolha, 2014) apoia a pena de morte ${ }^{3}$ ainda que seja o direito à vida uma cláusula pétrea da Constituição Brasileira. Aqueles que escreveram constituições tinham que raciocinar sobre princípios básicos e valores universais, assim como direitos (e deveres) comuns a todos os seres humanos, como a vida e a saúde. Raciocinar moralmente por princípios é próprio do nível Pós-Convencional. Mas a maioria votante e seus "representantes" raciocinam com a manutenção da ordem e da autoridade, daí defenderem a pena de morte como solução para crimes, o que é próprio do nível Convencional; somando-se com aqueles que defendem a Lei do Talião, expressão do nível Pré-Convencional (Rique et al., 2013).

As análises sobre o comportamento eleitoral do brasileiro nas últimas eleições presidenciais ilustram este predomínio da Identificação como processo de influência social: "No voto por identificação, o eleitor valoriza sobretudo o ator e sua ação, em detrimento dos obstáculos e da realização do objetivo propriamente dito" (Balbachevsky \& Holzhacker, 2004, p. 246). Tanto em 2002 quanto em 2006, “o voto em Lula em específico 
é mais fortemente explicado pela simpatia e identidade com o candidato" (Holzhacker \& Balbachevsky, 2007, p. 283). Assim, esse candidato obteve $46,44 \%$ dos votos no $1^{\circ}$ turno e $61,27 \%$ no $2^{\circ}$ turno em 2002 , e $48,61 \%$ dos votos no $1^{\circ}$ turno e $60,83 \%$ dos votos no no $2^{\circ}$ turno em 2006 ${ }^{4}$. Evidentemente, a eleição de Dilma Roussef foi resultado dessa identificação ainda com Lula, que a "elegeu" antecipadamente. Não se podia esperar outra coisa dos eleitores brasileiros na ocasião. Aqueles que decidem por princípios, no nível da internalização, compõem apenas uma minoria que pôde aparecer mais claramente apenas nos primeiros turnos. Em 2006, os candidatos que foram para o $2^{\circ}$ turno - Geraldo Alckmin e Lula - tinham principalmente a economia (geração de empregos, aumento do salário mínimo) como meio de atrair o voto do eleitor, obtendo juntos $90,24 \%$ dos votos.

Para uma análise da representação política da população na definição das leis, teremos como foco o Congresso Nacional, poder Legislativo, composto de Câmara dos Deputados e Senado Federal (excluindo o Tribunal de Contas da União, por seus membros não serem eleitos). Escolhemos a Câmara dos Deputados devido a serem 513 deputados federais idealmente representando o povo (enquanto são 81 senadores representando estados), podendo assim perceber uma composição entre os deputados unidos em grupos, em função do que esses concretamente "representam". $\mathrm{Se}$ avaliarmos a representatividade social dos deputados federais do Brasil em 2016 em função dos grupos de interesses - bancadas -, conforme a Tabela 3 , podemos fazer uma inferência.
Podemos ver que a bancada dos Direitos Humanos atualmente não chega a 5\% dos congressistas brasileiros, e mesmo que se aliasse à Bancada da Saúde, chegando a $8 \%$, o conjunto continuaria muito menor do que o mínimo necessário para ter qualquer efeito nas votações do Congresso Nacional. Podemos inferir que os deputados federais e senadores das outras bancadas que compõem maioria foram predominantemente eleitos pela população como resultado dos processos de obediência e identificação, conseguidos pelo poderio econômico (próprio e/ou dos grupos que concretamente representam). A influência social se dá quer seja diretamente por ofertas aos eleitores, quer seja indiretamente por meio do investimento nas campanhas publicitárias dos políticos, as quais promovem processos de identificação.

\section{E o papel das minorias ativas?}

Podemos, como possibilidade de transformação social dentro do sistema democrático, recorrer à Teoria das Minorias Ativas, de Moscovici, para encontrar meios de mudança social. A Teoria das Minorias Ativas apareceu pela primeira vez em um capítulo de livro (Moscovici \& Faucheux, 1972), e depois em livro (Moscovici, 2011). Nessa obra, o psicólogo social, que é mais conhecido por sua Teoria das Representações Sociais, afirma que é possivel que uma minoria difunda ideias e propostas contrárias àquelas da maioria, uma inovação. É preciso que lembremos que Moscovici faz uma crítica ao modelo funcionalista da influência

Tabela 3 Número de Deputados Federais participantes de cada bancada na Câmara em 2016

\begin{tabular}{lcl}
\hline \multicolumn{1}{c}{ BANCADA } & $\begin{array}{c}N^{\mathbf{0}} \text { DE } \\
\text { DEPUADOS }\end{array}$ & \multicolumn{1}{c}{ PARTIDOS PREDOMINANTES } \\
\hline PARENTES* & 238 & $\begin{array}{l}\text { PMDB (39), PSDB (26), PP (24), PSD (19), PSB(18), PT e PR } \\
\text { (15 cada) }\end{array}$ \\
\hline $\begin{array}{l}\text { EMPREITEIRAS / CON- } \\
\text { STRUTORAS }\end{array}$ & 226 & PT (41), PSDB (26), PP (25), PMDB (23), DEM (15), PSD (14) \\
\hline EMPRESARIAL & 208 & PMDB (30), PP (28), PSDB (26), PSB e PR (15 cada) \\
\hline RURALISTAS & 207 & PMDB (45), PP (19), PSDB (18), PSD (17), PR (16) \\
\hline EVANGÉLICA & 196 & $\begin{array}{l}\text { PMDB (21), PSDB (20), PRB (17), PSB (16), PSD E PP (14 } \\
\text { cada) }\end{array}$ \\
\hline SINDICAL & 43 & PT (27), PCdoB (4) \\
\hline BALA & 35 & PMDB (7), DEM (5), PR (4), PSDB e PSD (3 cada) \\
\hline DIREITOS HUMANOS & 24 & PT (12), PSol (5), PCdoB (3), PSB (2) \\
\hline MINERAÇÃO & 23 & PMDB (4), PSD (3), PT, PSDB, PR e PP (2 cada) \\
\hline SAÚDE & 21 & PT (5), PDT (3), PSDB, PMDB e PCdoB (2 cada) \\
\hline BOLA & 14 & PTB (3), PSD (3), PT (2) \\
\hline SEM BANCADA & 15 & PT (3), PMDN e PSB (2 cada) \\
\hline
\end{tabular}

* Aqueles tendo parentes políticos desde as eleições de 2002. Fonte: http://apublica.org/2016/02/truco-as-bancadas-da-camara/ 
social na psicologia social norte-americana - de Asch, Festiger, Sherif-, em que apenas O influencia $P$, e não se leva em conta que também $\mathrm{P}$ influencia $\mathrm{O}$ (Moscovici, 2011). Lembramos disso para podermos entender que não só a maioria influencia a minoria, mas esta última também influencia a maioria. Kelman também afirma estar ciente da questão da unilateralidade ${ }^{5}$, admitindo a mutualidade da influência, e justifica por que não a inclui em sua análise: "I felt it necessary to specify $O$ and $P$ - the agent and the target of influence - for any given episode of interaction" (Kelman, 2006, p. 7). Moscovici não cita o trabalho de Kelman sobre influência social até 1979; passa a citá-lo apenas quando propõe o processo de "conversão" da maioria (Moscovici, 1980).

Moscovici então assume - em seu modelo genético da influência social - a tarefa de mensurar o efeito inovador de uma minoria dentro de um grupo, por meio de conflito com a maioria, e oferece a análise da atuação de minorias ativas que trazem inovações em grupos sociais. Distiguiu que para isso é necessário que a minoria tenha um "estilo comportamental" compartilhado por todos que a compõem, em que cumpra três condições:

1. Ter consciência da relação que existe entre o estado interior e os signos externos que eles utilizam. A certeza se expressa em tom afirmativo, seguro; por exemplo, a intenção de não fazer concessões expressase na firmeza do comportamento adequado.

2. Utilizar sinais de modo sistemático e consistente, a fim de evitar um mal-entendido por parte do receptor.

3. Conservar as mesmas relações entre os comportamentos e as significações ao longo de uma interação; em outros termos, assegurar que as palavras não mudem de significado no curso da interação. (Moscovici, 2011, p. 118).

Quanto aos estilos de comportamento da minoria ativa, Moscovici pondera que há cinco estilos necessários: o esforço, a autonomia, a consistência, a rigidez (inicial) e a equidade, dando especial atenção à consistência (Moscovici, 2011, p. 119), como sendo "fundamental": De uma parte, expressa ou uma firme conviçção em circunstâncias nas quais opiniões são habitualmente menos seguras, ou uma solução de troca válida a opiniões dominantes. De outra parte, um indivíduo que desempenha um comportamento muito consistente não só parece muito seguro de si mesmo, senão que garante também que um acordo com ele levará a um consenso sólido e duradouro. (Moscovici, 2011, p. 130)
Então é possível que uma minoria ativa influencie uma maioria para aceitar sua agenda, pelo processo denominado "conversão" (Moscovici, 1980), trazendo uma inovação social. Se pensarmos em estratégias educativas para facilitar a passagem do pensamento egocêntrico para o sociocêntrico, sem cair na forma de Pensamento de Grupo ou, se cair, saber sair dele; e se queremos adultos capazes de pensar por si só, para que haja na sociedade uma maioria que se conduza segundo a ética universal, então é preciso pensar em educação pública que leve a isso, e para pensar nessa educação é preciso pensar em Direitos Humanos. E, para isso, precisamos da atuação de uma minoria ativa que - raciocinando por princípios éticos universais - seja capaz de lutar pela aplicação concreta da Constituição no referente aos Direitos Humanos, e cuja bancada correspondente seja capaz de agir sobre a maioria a ponto de tornar a agenda dos Direitos Humanos a prioridade aceita por uma maioria. Essa minoria então busca por meio do conflito de ideias a "conversão" psicológica daqueles pertencentes à maioria, a qual atualmente defende os valores econômicos que levam ao sacrifício do futuro pelo ganho presente. Enquanto os valores da educação exigem sacrificar parte do ganho presente pelo ganho futuro, é preciso investimento financeiro e humano na escolarização crescente da população para que atinjam a capacidade do pensamento abstrato mais avançado por meio de professores engajados na realização e defesa dos Direitos Humanos; e os resultados demorarão muitos anos para aparecer. É preciso persistir consistentemente, dado que "a minoria exerce sempre certo influxo sobre a maioria e pode incitar à modificação do seu comportamento ou sua atitude, para induzi-la a ser mais tolerante com o que antes estava excluído ou proibido" (Moscovici, 2011, p. 75). Isto é bem diferente do processo de "normatização" descrito por Moscovici, em que tudo que se faz é para evitar o conflito e "impedir o desacordo em relação ao esquema de referência" (Moscovici, 2011, p. 182), propiciando assim o Pensamento de Grupo.

Para entender o que é preciso mudar, basta analisar os tamanhos das bancadas dos grupos de interesse entre os deputados federais, que em sua grande maioria representam organizações empresariais - e não populações - e suas capilaridades. As bancadas com mais deputados em comum são: parentes e empreiteiras/construtoras (com representantes em todas as outras bancadas); evangélica e agropecuária (com representantes em todas, exceto Direitos Humanos); empresarial (com representantes em todas, exceto a sindical). Para uma melhor noção dessa capilaridade, vide a Tabela 4. 
Tabela 4. Quantidade de bancadas em que os Deputados Federais participaram em 2016

\begin{tabular}{cc}
\hline $\mathbf{N}^{\mathbf{o}}$ total de Bancadas & $\begin{array}{c}\text { Total de Deputados } \\
\text { Federais }\end{array}$ \\
\hline 0 & 15 \\
\hline 1 & 108 \\
\hline 2 & 165 \\
\hline 3 & 124 \\
\hline 4 & 81 \\
\hline 5 & 19 \\
\hline 6 & 1 \\
\hline Total Geral & 513 \\
\hline
\end{tabular}

Fonte: http://apublica.org/2016/02/truco-as-bancadas-da-camara/

Se quisermos uma mudança social que se revele na composição da Câmara dos Deputados, teremos uma situação inversa, em que os interesses da população geral estejam fortemente representados, e isso pode ser compreendido como uma "bancada" dos Direitos Humanos, suficientemente grande, no sentido de poder fazer maiorias, simples ou qualificada. Para isto, uma bancada dos Direitos Humanos deve agir organizada e sistematicamente, buscando mudar o comportamento da maioria debatendo as ideias, provocando o conflito de prioridade desse interesse com os outros dominantes na Câmara dos Deputados, até colocar os Direitos Humanos como prioridade da Câmara e do Senado.

\section{Conclusão}

Neste ensaio, não abordamos diretamente a questão de como uma minoria ativa pode, no Congresso Nacional, chegar a intervir na educação de modo que esta conduza a maioria das pessoas a se tornarem adultos com capacidade cognitiva e moral próprias do Nível Pós-Convencional. Assim, essa mesma minoria inicial de adultos que se apropriaram da oportunidade de raciocinar no Nível Pós-Convencional e agir de acordo com isso pode se unir, adotando nos grupos e na sociedade o estilo comportamental descrito por Moscovici como típico da minoria ativa, assim como comporá um eleitorado que poderá ter crescentemente representantes na bancada dos Direitos Humanos, em um processo recursivo. Esse processo educacional deverá ser tema de outro ensaio, já com base em pesquisas que demonstram o efeito da educação no avanço do raciocínio moral (Moreira, Camino, \& Rique, 2015).
Buscar a mudança social contra a fome e a doença (que ofendem a vida), a violência (que ofende a paz), a opressão (que ofende a liberdade), a exploração (que ofende a igualdade), a discriminação e a iniquidade entre homens e mulheres (que ofendem a justiça), a crueldade e a negligência (que ofendem a fraternidade e o amor); posicionando-se sempre em defesa da aplicação desses princípios e mudando a aceitação da maioria, em busca da realização dos direitos fundamentais, a prática e a defesa do respeito absoluto à dignidade humana, conforme a nossa Constituição bem o prescreve, pode ser um ótimo começo.

\section{Notas}

"I use the term groupthink as a quick and easy way to refer to the mode of thinking that persons engage in when concurrence-seeking becomes so dominant in a cohesive ingroup that it tends to override realistic appraisal of alternative courses of action. Groupthink is a term of the same order as the words in the newspeak vocabulary George Orwell used in his dismaying world of 1984. In that context, groupthink takes on an invidious connotation. Exactly such a connotation is intended, since the term refers to a deterioration in mental efficiency, reality testing and moral judgments as a result of group pressures." (Janis, 1971)

2 no kantismo, proposição concebida pela razão impessoal como uma exigência para todos os seres humanos, que consiste em um princípio puramente formal de universalização consentida e desejada dos comportamentos (Dicionário eletrônico Houaiss da Língua Portuguesa 3.0).

3 De 1991 a 2008, média de 52\% apoiando a pena e de 43\% contra, segundo o Datafolha (Datafolha, 2014); já entre os eleitores em 2014, $43 \%$ apoiando e $52 \%$ contra a pena de morte. Fonte: http://datafolha.folha.uol.com.br/ eleicoes/2014/09/1512693-direita-supera-esquerda-nobrasil.shtml

4 Fonte: Tribunal Superior Eleitoral: http://www.tse.jus.br/ eleicoes/eleicoes-anteriores/eleicoes-2002/resultado-daeleicao-2002

5 "I was well aware that influence flows in both directions in social interactions" (Kelman, 1958, p. 7).

\section{Referências}

Asch, S. E. (1977). Psicologia Social. São Paulo: Companhia Editora Nacional .

Balbachevsky, E. \& Holzhacker, D. O. (2004). Identidade, oposição e pragmatismo: o conteúdo estratégico da decisão eleitoral em 13 anos de eleições. Opinião Pública,10(2), 242 $-253$.

Crochík, J. L. (2006). Preconceito, individuo e cultura (3a ed.). São Paulo: Casa do Psicólogo.

Edwards, C. P. (1980). The development of moral reasoning in cross-cultural perspectiHandbook of cross-cultural human development. New York: Garland Press.

Fini, L. D. (1991). Desenvolvimento moral: de Piaget a Kohlberg. Perspectiva , 9(16), 58-78. 
Holzhacker, D. O. \& Balbachevsky, E. (2007). Classe ideologia e política: uma interpretação dos resultados das eleições de 2013. Opinião Pública, 13(2), 283-306.

Janis, I. L. (1971). “Groupthink”. Psychology Today, 5(6), 43-46.

Kelman, H. C. (1958). Compliance, identification, and internalization: three processes of attitude change. Journal of Conflict Resolution, 2(1), 51-60.

Kelman, H. C. (2006). Interests, Relationships, Identities: Three Central Issues for Individuals and Groups in Negotiating Their Social Environment. Annu. Rev. Psychol. , 57, 1-26.

Kohlberg, L. \& Hersh, R. H. (1977). Moral Development: a review of the theory. Theory into Practice, 16(2), 53-59.

Medeiros, C. A., Albuquerque, L. G., Siqueira, M., \& Marques, G. M. (2003). Comprometimento organizacional: o estado da arte da pesquisa no Brasil. Revista de Administração Contemporânea , 7(4), 187-209.

Moreira, P. L., Camino, C. P. S., \& Rique, J. (2015). Uma comparação do desenvolvimento moral de adolescentes entre duas décadas. Arquivos Brasileiros de Psicologia, 67(3), 47-61. Recuperado

de http://pepsic.bvsalud.org/pdf/arbp/v67n3/05.pdf

Moscovici, S. (2011). Psicologia das minorias ativas. Petrópolis, RJ: Vozes.

Moscovici, S. (1980). Toward a theory of conversion behavior. In L. Berkowitz (Ed.), Advances in experimental social psychology (Vol. 13, pp. 209-239). New York: Academic Press.

Moscovici, S. \& Faucheux, C. (1972). Social influence, conformity bias, and the study of active minorities. In
L. Berkowitz (Ed.), Advances in experimental social psychology (Vol. 6, pp. 150-202). New York: Academic Press.

Paín, S. (1992). Psicometria genética. São Paulo: Casa do Psicólogo.

Piaget, J. (1965). The Moral Judgment of the Child. New York: Free Press.

Robbins, S. P., Judge, T. A., \& Sobral, F. (2010). Comportamento organizacional. (14a ed.). São Paulo: Pearson.

Submissão em: 12/12/2016

Revisão em: 19/12/2017

Aceitar 31/01/2018

Paulo Roberto Grangeiro Rodrigues é psicólogo, mestre e doutor em Psicologia Social pelo Instituto de Psicologia da USP, SP. Professor no Departamento de Psicologia de Universidade de Taubaté, professor e pesquisador do Programa de Gestão e Desenvolvimento Regional da Universidade de Taubaté.

Endereço para correspondência: Departamento de Psicologia. Universidade de Taubaté. Av. Tiradentes, 500, Jardim das Nações, Taubaté /SP, Brasil. CEP 12030-180. E-mail: paulo.grangeiro@unitau.com.br 